\title{
Investigation on the use of cutting temperature and tool wear in the turning of mild steel bars
}

\author{
K. Abou-El-Hossein*and N. Kops \\ Precision Engineering Laboratory, Department of Mechatronics, \\ Nelson Mandela University, Port Elizabeth, South Africa \\ *Email: khaled.abou-el-hossein@mandela.ac.za \\ Phone: +27415043368
}

\begin{abstract}
The paper is concerned with the development of a data acquisition system for the measurement of temperature used for metal cutting. In this study, machining tests were performed and an analysis of the temperature and wear of the cutting tool is presented herein. In metal cutting operations, the wear of tools is generated largely due to the heat emitted from the cutting zone. Therefore, a coolant is often used to cool down the cutting area and protect the cutting tools. However, because of environmental concerns, engineers now try to avoid using cutting coolants and perform cutting operations in almost dry conditions. In this study, a mild-steel round bar was turned at various feed rates, depths of cut and cutting speeds. A data acquisition system was built to record the cutting temperature while turning the bar. From the study, it is evident that certain combinations of cutting parameters result in higher temperatures than those produced in other experiments. It was established that the depth of cut and cutting speed at their highest values $(1 \mathrm{~mm}$ and $250 \mathrm{~m} / \mathrm{min}$, respectively) contribute largely to the high surface temperature, while the effect of feed rate is intangible. Increasing the cutting speed results in an increase in the cutting temperature. A similar result was observed when the depth of cut was increased. However, increases in feed rate did not significantly cause increases in cutting temperature. In addition, cutting inserts were examined under a scanning electron microscope (SEM) to quantify the tool wear in each experiment. A correlation between tool wear and temperature is clearly noticed. The study concluded that the combination of variations in cutting speed and depth of cut results in severe tool wear action on the tool's flank face as a result of the intensive heat generated.
\end{abstract}

Keywords: Machining; turning of mild steels; cutting temperature; flank wear.

\section{INTRODUCTION}

Metal cutting is a common material-processing operation used to make mechanical components. It is realised in a very complex environment and until now has still not been completely investigated. Increasing the productivity and quality of machined parts is a core challenge in the machining industry [1]. Certain processing parameters can largely affect the level of productivity, quality, and overall economy of machined parts. These parameters include tool life and wear, surface finish, part accuracy, cutting forces, material removal rate, power consumption rate, and cutting temperature (on the tool and workpiece). In the cutting of materials, the majority of power is converted into heat, thus resulting in extremely high cutting temperatures in the cutting zone [2]. Temperatures in 
the cutting zone depend on the extent of contact length, cutting forces, and friction between the tool and workpiece [3]. The amount of heat generated varies with the type of material being machined and machining parameters employed, especially the cutting speed [4]. The temperature rise in the cutting zone may limit the cutting speed and depth of cut, causing extensive tool wear that may quickly deteriorate the tool's life and create thermal stresses in the machined material and distortions of its surface [5]. The heat generated in the cutting zone is shared by the chip, cutting tool, and the workpiece. $10 \%$ to $20 \%$ of the total heat goes into the tool, while some heat is absorbed into the work piece [6]. There is no doubt that the cutting efficiency gets improved if the cutting temperature is maintained at low levels. The effect of the cutting temperature is detrimental to the life of the tool and the workpiece surface quality.Literature contains a lot of reports on experimental studies that are based on experiments that have utilised various techniques meant for determining the cutting temperature and its distributions along the cutting edge of the tool [7-13]. Such studies have been successful in accurately predicting the cutting temperature, thanks to the new improvements and developments in instrumentation and data acquisition techniques. The techniques for the measurements of cutting temperature have evolved over time. These include the use of embedded thermo-couples, infrared radiation sensors, thermo-sensitive painting, and metallographic methods that are based on determining the material's microstructure alteration. The most extensively used method is the tool-work thermocouple. This method is useful in showing the effect of cutting conditions such as cutting speed and feed rate, but the absolute values of the temperature measured are inaccurate [14]. However, by using thermocouples with small diameters, it is possible to obtain good results in relation to the temperature gradient in a tool by inserting many thermocouples in small holes close to the cutting edge [14]. A more advanced and complicated method is by measuring the cutting temperature using built-in thin film thermocouple sensors. This technique works very well in accurately monitoring and predicting the temperature [15].

The purpose of this paper is to present an investigation of the cutting temperature produced when varying three cutting parameters: cutting speed, depth of cut and feed rate when machining a mild-steel grade. The objective of the study is to establish a relationship between cutting temperature and tool wear. A data acquisition system was built to measure the cutting temperature while turning a mild steel grade.

\section{METHODS AND MATERIALS}

The aim of this experimental investigation is to establish the effect of cutting parameters on tool inserts' flank wear and cutting temperature. The turning tests were conducted with the help of the design of experiments (DOE) methodology. DOE refers to the process of planning experiments so that the appropriate data can be analysed using statistical methods which result in valid and objective conclusions. The experiments were conducted according to a three-level Taguchi orthogonal array design. The cutting parameters identified are the cutting speed, depth of cut, and feed rate. The control parameters and the level used in the experiment, experimental setup and conditions are as given in Table 1 . These parameters were selected based upon the maximum ratings of the lathe machine and considering the initial observations of tool insert failures obtained at the preliminary stage of the preparatory experimentation conducted to establish the practical boundaries of machining parameters and their ranges. In this design of experiments, the axial point central composite design was adopted as the design of the experiment. 
An AISI 1018 mild steel round bar of $\varnothing 55 \times 300 \mathrm{~mm}$ was turned in this study. The material has the yield and tensile strengths of 370 and $440 \mathrm{MPa}$, respectively. The workpiece was checked for its surface hardness, and an average value of HRB 71 was obtained. The chemical composition of the machined workpiece is shown in Table 2.

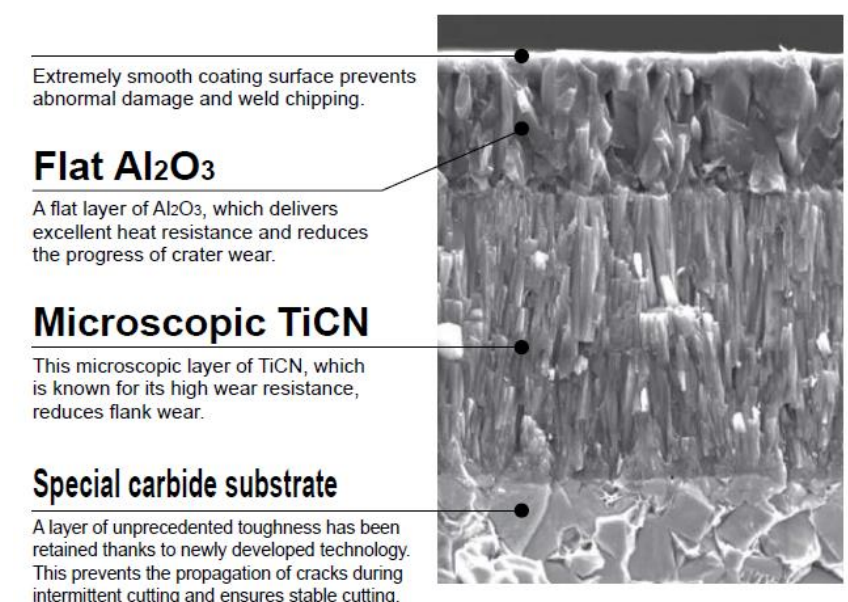

Figure 1. Multilayer-coated insert (TNMG160404-MA).
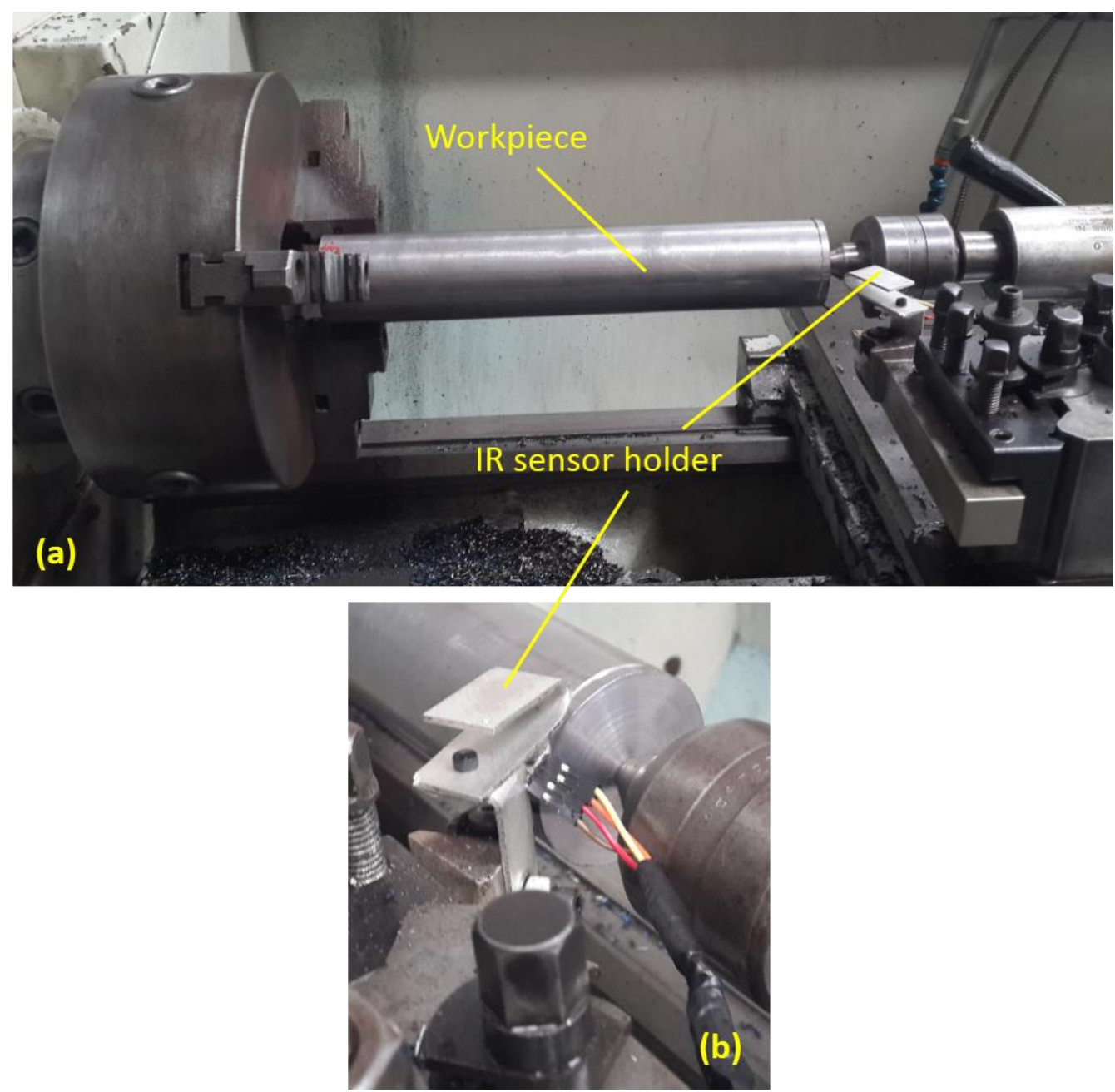

Figure 2. Experimental setup: (a) general view; (b) closeup view 
Table 1. Cutting parameters and their levels.

\begin{tabular}{llccc}
\hline \multicolumn{1}{c}{ Parameter } & \multirow{2}{*}{ Unit } & \multicolumn{3}{c}{ Level } \\
\cline { 3 - 5 } & & Low & Middle & High \\
\hline Depth of cut $(D)$ & $(\mathrm{mm})$ & 0.5 & 0.75 & 1 \\
Feed rate $(F)$ & $(\mathrm{mm} / \mathrm{rev})$ & 0.15 & 0.2 & 0.25 \\
Cutting speed $(V S)$ & $(\mathrm{m} / \mathrm{min})$ & 150 & 200 & 250 \\
\hline
\end{tabular}

Table 2. Chemical composition of AISI 1080.

\begin{tabular}{cccccc}
\hline Element & $\begin{array}{c}\text { Carbon, } \\
\mathrm{C}\end{array}$ & $\begin{array}{c}\text { Manganese, } \\
\mathrm{Mn}\end{array}$ & $\begin{array}{c}\text { Phosphorous, } \\
\mathrm{P}\end{array}$ & $\begin{array}{c}\text { Sulphur, } \\
\mathrm{S}\end{array}$ & $\begin{array}{c}\text { Iron, } \\
\mathrm{Fe}\end{array}$ \\
\hline$\%$ & $0.14-0.20$ & $0.60-0.90$ & $\leq 0.040$ & $\leq 0.050$ & $98.81-99.26$ \\
\hline
\end{tabular}
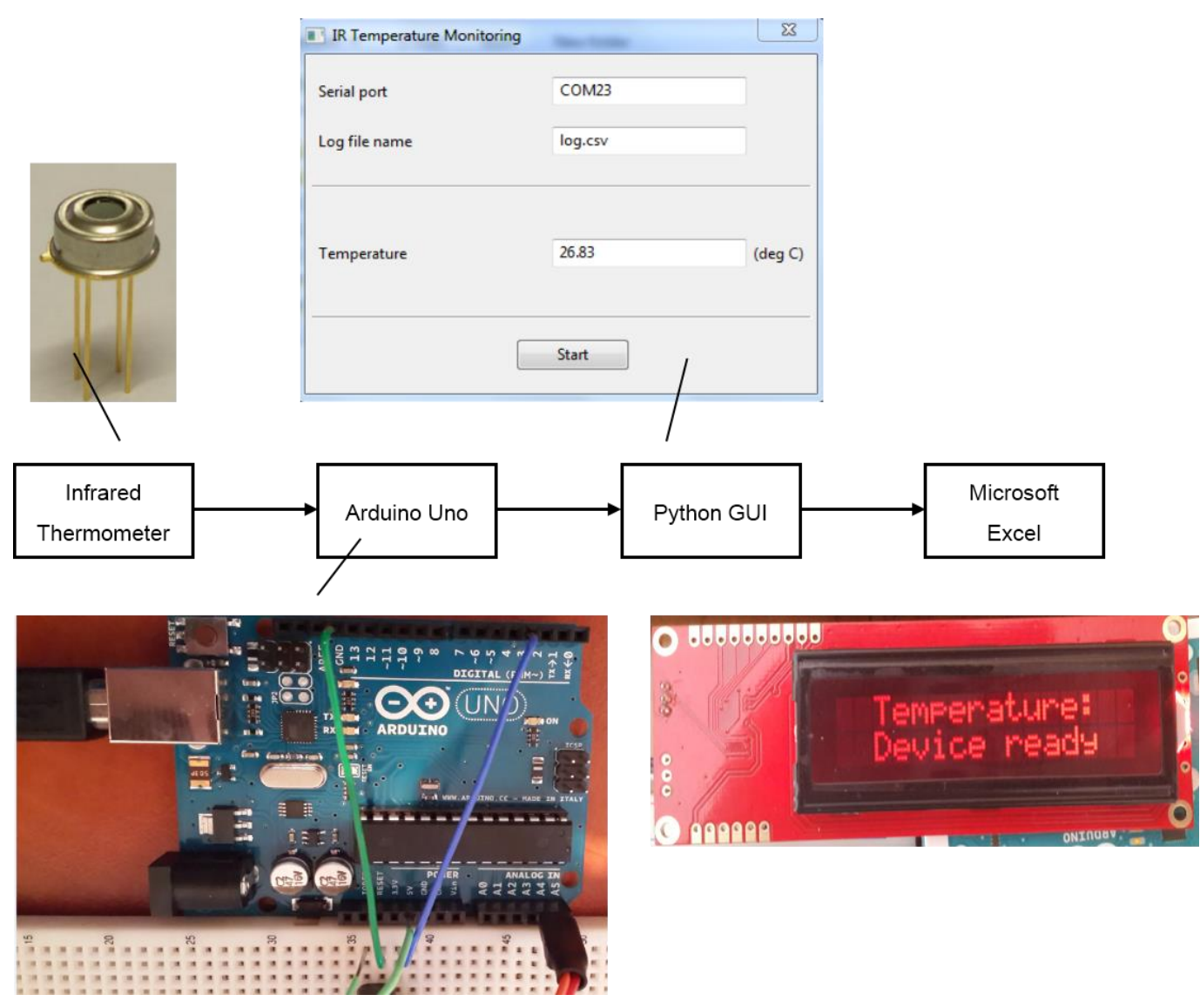

Figure 3. Block diagram of the data acquisition system.

Lathe cutting inserts (TNMG160404-MA) from Mitsubishi Tooling were used in turning. The inserts had multiple layers of coatings that consist of $\mathrm{Al}_{2} \mathrm{O}_{3}$ and $\mathrm{TiCN}$ (Figure 1). This coating combination provides heat and wear resistance and helps maintain the maximum tool life of the inserts. In addition, the cutting inserts contain a chip breaker to control the chips during the cutting process. The technique of measuring temperature using radiation is useful in obtaining the surface temperature of the 
workpiece, the chip, and the tool. Methods for measuring temperature based on radiation are known as non-contact methods. In this study, an infrared sensor (Figure 2) compatible with many microprocessors was used to measure the cutting temperature. A commercially available infrared sensor (Melexis MLX90614) was mounted on a bracket in such a way that it would not be damaged by the chips during cutting. The position of the sensor with respect to the measured target was tuned with the help of a laser-based setting device. The block diagram shown in Figure 3 represents the data acquisition system. The data acquisition system is comprised of an infrared sensor to capture the cutting temperature, a liquid crystal display (LCD) screen to display commands and cutting temperature, and a microprocessor to control and manage the system. A Graphical User Interface (GUI) was designed using Python. It was necessary to create a multithread in order to store the temperature measurements in an excel file and display it on the LCD display.

\section{RESULTS AND DISCUSSION}

Table 2 shows the experimental combinations as designed according to the Taguchi method. The workpiece surface temperature was monitored for each experiment run and graphs were plotted for each run. Table 2 also shows the workpiece's highest surface temperature at the cutting zone for each run of the experiment. It is evident that the workpiece's highest surface temperature was recorded in Run \#9 with a cutting speed 250 $\mathrm{m} / \mathrm{min}$, a 1-mm depth of cut and a feed rate of $0.2 \mathrm{~mm} / \mathrm{rev}$ (Figure 4). A general observation of all of the experimental runs indicate that the depth of cut and cutting speed contribute largely to the surface temperature, while the effect of feed rate is intangible. This could be attributed to the inability of the cutting inserts to maintain their sharp cutting geometry at increased cutting speeds and feed rates. It was evident from the experiments that the inserts maintained good cutting edges at different feed rates for the same cutting speeds and feed rate values. In addition, there is a big chance that built-up edge (BUE) was developed at the far edge at higher speed rates, resulting in more dull cutting edges on the tool and consequently, higher cutting temperatures [16].

Table 2. Workpiece surface temperature.

\begin{tabular}{ccccc}
\hline Run \# & $\begin{array}{c}\text { Cutting Speed, } \\
(\mathrm{m} / \mathrm{min})\end{array}$ & $\begin{array}{c}\text { Depth of Cut, } \\
(\mathrm{mm})\end{array}$ & $\begin{array}{c}\text { Feed Rate, } \\
(\mathrm{mm} / \mathrm{rev})\end{array}$ & $\begin{array}{c}\text { Temperature, } \\
\left({ }^{\circ} \mathrm{C}\right)\end{array}$ \\
\hline 1 & 150 & 0.5 & 0.15 & 66 \\
2 & 150 & 0.75 & 0.2 & 57 \\
3 & 150 & 1 & 0.25 & 77 \\
4 & 200 & 0.5 & 0.2 & 60 \\
5 & 200 & 0.75 & 0.25 & 67 \\
6 & 200 & 1 & 0.15 & 65 \\
7 & 250 & 0.5 & 0.25 & 81 \\
8 & 250 & 0.75 & 0.15 & 70 \\
9 & 250 & 1 & 0.2 & 95 \\
\hline
\end{tabular}

To validate the findings mentioned above, further experimentation was conducted to confirm the effect of the cutting speed on the cutting temperature. Therefore, the depth of cut was kept constant at $0.5 \mathrm{~mm}$. It was found that that as the cutting speed increased, so did the cutting temperature. Also, the same was observed when varying the feed rate at a constant depth of cut. However, the effect of varying the depth of cut was established 
to be negligible when fixing both the feed rate and cutting speed. Since the cutting temperatures are now known, it was necessary to correlate the temperature to the tool wear [17]. An SEM was used to determine the flank wear on the cutting inserts. The flank wear occurs on the tool flank as a result of friction between the machined surface of the workpiece and the tool flank which resulted in the gradual chipping of the cutting edge. Flank wear greatly affects the cutting process by increasing the cutting forces $[18,19]$.

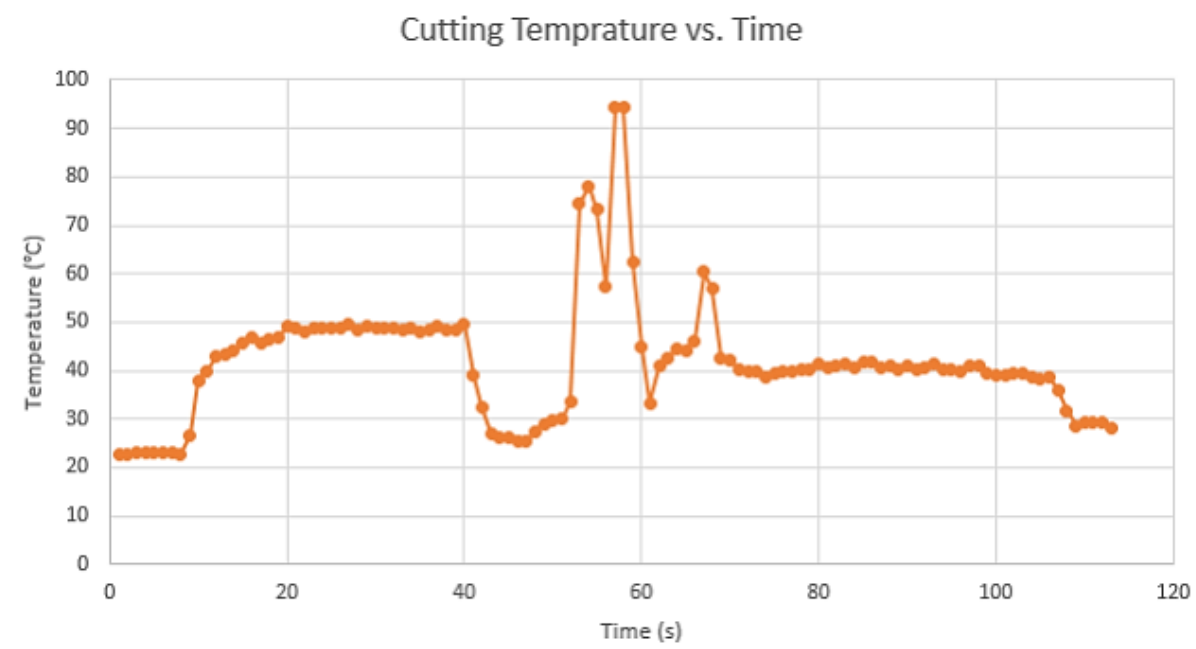

Figure 4. Temperature measurement in Run \# 9.

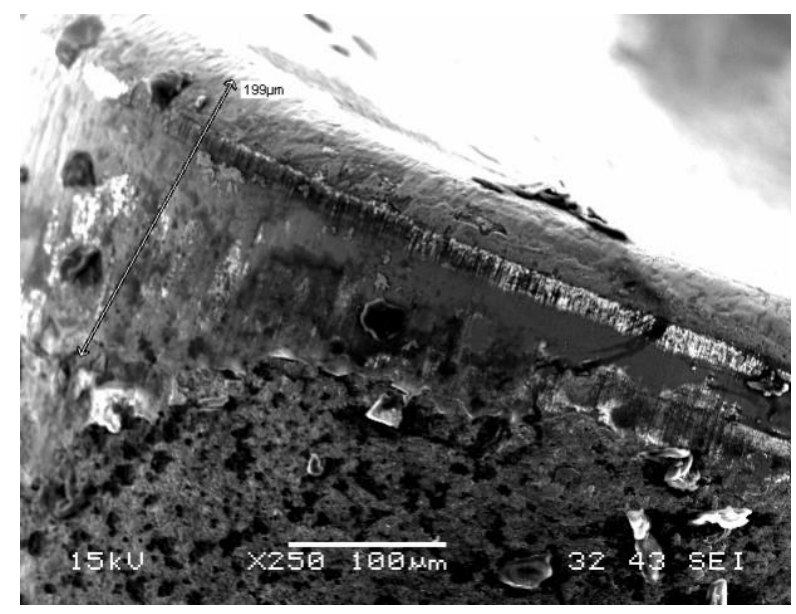

Figure 5. Flank wear for experimental run No. 9.

Figure 5 shows an SEM image of the cutting tool of experiment No. 9 which employed the highest cutting parameters. In this run which resulted in the highest temperature, the tool suffered the highest wear recorded in this study. The maximum flank wear, in this case, is $199 \mu \mathrm{m}$. This wear may be largely caused by the effect of the high cutting speed used. The temperature measured for this experiment run was $95^{\circ} \mathrm{C}$. The dark areas on the flank's face were a result of the excessive heat generated during machining. One can conclude in this regard that with the increase in cutting velocity, the flank wear increased as a result of fast chipping action influenced largely by high temperatures and the lack of lubrication [20].

Figure 6 shows an SEM image of the cutting insert used for experiment 2 which resulted in the lowest cutting temperature $\left(57^{\circ} \mathrm{C}\right)$ with a depth of cut of $0.75 \mathrm{~mm}$, a feed 
rate of $0.2 \mathrm{~mm} / \mathrm{rev}$ and a cutting speed of $150 \mathrm{~m} / \mathrm{min}$. Only a flank wear land of $27 \mu \mathrm{m}$ width was obtained in this case. Therefore, one can conclude that low cutting temperatures increase the life of tools. With a lower cutting speed, the friction is reduced as a result of low cutting forces, and this will reduce the amount of heat generated.

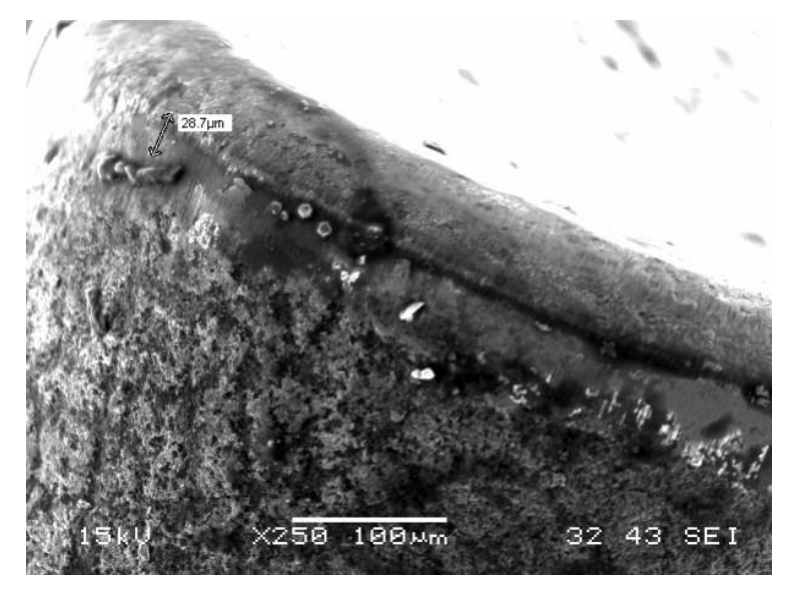

Figure 6. Flank wear for experimental run No. 2.

\section{CONCLUSIONS}

A data acquisition system to monitor the cutting temperature in the turning operations of a mild steel grade (AISI 10180) was successfully implemented. The system has proven to be easy to use and provided sound results for data analysis purposes. In this study, it was established that the depth of cut and cutting speed have larger effects on cutting temperature compared to feed rate. When the tool was employed at highest cutting speed and depth of cut, a maximum flank wear of $199 \mu \mathrm{m}$ was obtained, while the lowest wear of $27 \mu \mathrm{m}$ was obtained at the lowest cutting speed and feed rate. A high feed rate; however, causes uniform wear on the tool. It was shown that temperature has a direct impact on flank wear and the life of the cutting tool. Therefore, cutting parameters need to be properly and optimally selected to reduce the cutting temperature. However, there has to be a balance between surface finish, processing time and tool wear.

\section{ACKNOWLEDGEMENTS}

The authors would like to thank the staff members of the mechanical workshop at the Nelson Mandela University for their help with the use of the lathe machine and materials testing laboratory. Also, would like to thank Mr Glynne Erasmus for his assistance with operating the SEM.

\section{REFERENCES}

[1] Stephenson DA, Agapiou JS. Metal cutting theory and practice: CRC press; 2016.

[2] Grzesik W. Advanced machining processes of metallic materials: theory, modelling and applications: Elsevier; 2008.

[3] Shaw MC, Cookson J. Metal cutting principles: Oxford university press New York; 2005.

[4] Bhoyar Y, Kamble P. Finite element analysis on temperature distribution of turning process. Int J Mod Eng Res. 2013;3:541-6. 
[5] Aggarwal A, Singh H. Optimization of machining techniques - a retrospective and literature review. Sadhana. 2005;30:699-711.

[6] Sayuti M, Sarhan AA, Hamdi M. An investigation of optimum $\mathrm{SiO}_{2}$ nanolubrication parameters in end milling of aerospace Al6061-T6 alloy. The International Journal of Advanced Manufacturing Technology. 2013:1-17.

[7] Odedeyi P, Abou-El-Hossein K, Liman M. An experimental study of flank wear in the end milling of AISI 316 stainless steel with coated carbide inserts. Journal of Physics: Conference Series: IOP Publishing; 2017. p. 012058.

[8] Abou-El-Hossein K. Effect of Minimum quantity lubrication when turning a steel grade. Applied Mechanics and Materials: Trans Tech Publ; 2014. p. 392-6.

[9] Yogeswaran M, Kadirgama K, Rahman M, Devarajan R. Temperature analysis when using ethylene-glycol-based $\mathrm{TiO}_{2}$ as a new coolant for milling. International Journal of Automotive and Mechanical Engineering. 2015;11:2272-81.

[10] Najiha M, Rahman M, Yusoff A, Kadirgama K. Investigation of flow behavior in minimum quantity lubrication nozzle for end milling processes. International Journal of Automotive and Mechanical Engineering. 2012;6:768-76.

[11] Singh R, Singh B. Comparison of cryo-treatment effect on machining characteristics of titanium in electric discharge machining. International Journal of Automotive and Mechanical Engineering. 2011;3:239-48.

[12] Puvanesan M, Rahman M, Najiha M, Kadirgama K. Experimental investigation of minimum quantity lubrication on tool wear in aluminum alloy 6061-t6 using different cutting tools. International Journal of Automotive and Mechanical Engineering. 2014;9:1538.

[13] Najiha M, Rahman M, Kamal M, Yusoff A, Kadirgama K. Minimum quantity lubricant flow analysis in end milling processes: A computational fluid dynamics approach. Journal of Mechanical Engineering and Sciences. 2012;3:340-5.

[14] Jeon J, Kim S. Optical flank wear monitoring of cutting tools by image processing. Wear. 1988;127:207-17.

[15] Basti A, Obikawa T, Shinozuka J. Tools with built-in thin film thermocouple sensors for monitoring cutting temperature. International Journal of Machine Tools and Manufacture. 2007;47:793-8.

[16] Reis LL, Silva Júnior WMd, Machado ÁR. Effect of cutting speed and cutting fluid on the BUE geometry of a SAE 12L14 free machining steel. Journal of the Brazilian Society of Mechanical Sciences and Engineering. 2007;29:196-201.

[17] Wanigarathne P, Kardekar A, Dillon O, Poulachon G, Jawahir I. Progressive toolwear in machining with coated grooved tools and its correlation with cutting temperature. Wear. 2005;259:1215-24.

[18] El Hakim M, Shalaby M, Veldhuis S, Dosbaeva G. Effect of secondary hardening on cutting forces, cutting temperature, and tool wear in hard turning of high alloy tool steels. Measurement. 2015;65:233-8.

[19] Wagner V, Baili M, Dessein G. The relationship between the cutting speed, tool wear, and chip formation during Ti-5553 dry cutting. The International Journal of Advanced Manufacturing Technology. 2015;76:893-912.

[20] Thamizhmanii S, Hasan S. Relationship between flank wear and cutting force on the machining of hard martensitis stainless steel by super hard tools. Proceedings of the World Congress on Engineering: World Congress on Engineering 2010; 2010. p. 2185-90. 